\title{
Multimodal literacy in academic environments: PowerPoint as a motivational genre
}

\author{
Stefania Consonni \\ stefania.consonni@unibg.it \\ Università degli Studi di Bergamo, Italy
}

\begin{abstract}
This paper explores PowerPoint (PPT) as a leading genre in academic discourse, focussing on the implementation of student motivation boosting strategies. ICT nowadays plays an increasingly important role in pedagogy, by reinforcing the informative and persuasive impact of instructional materials through multimodal strategies including verbal and visual codes, as well as performative elements. A hybrid genre in academic oratory, PPT offers corporeality of knowledge, modularity and easily transmittable format, providing presentations with structure and facilitating ordering and summarizing operations. PPT can therefore be ranked among today's epistemic machineries, whereby knowledge is construed by discourse. The paper analyses the semiotic and metadiscursive features of a corpus of presentations produced in various universities for both academic staff and students. Research questions explore how PPT can be used to motivate teachers and students, from both an ideational and interactional standpoint. An integrated analytical approach is employed, bridging multimodal and critical discourse analysis.
\end{abstract}

Keywords: Multimodality, PowerPoint, digital literacy, motivation, academic discourse, genre analysis

\section{INTRODUCTION}

This paper addresses the ways in which Information and Communication Technology (ICT), and particularly PowerPoint (PPT), is affecting the semiotic and linguistic features of academic communication, both in symmetric and asymmetric settings, with a specific focus on the dissemination and implementation of student motivation boosting strategies. Motivation is a major factor in today's pedagogy: as the Latin root of the word suggests, to motivate students means 'to move' them, i.e., to incentive or drive them to act in order to achieve specific results or goals (Williams and Williams 2011: 2). As socio-cognitive psychology indicates, motivation and cognition work in concert, in that individuals have the ability to discern how to regulate their behaviour so that it meets their learning goals (Eccles and Wigfield 2002: 123). Research on the psychopedagogy of foreign languages and the pedagogical influence of ICT (Dörnyei 2001; Dörnyei and Schmidt 2001) has shown in particular that students should be encouraged to play an active role in the educational process (Bellés-Fortuño and Ollero 2015: 146), 
for this can optimise the degree of their commitment to (and pleasure in) learning. This means that reluctant learners can become self-regulated learners, i.e., they can learn how to apply agency, purpose and self-efficacy beliefs, and set goals and performance outcomes for themselves.

Presentation software nowadays plays an increasingly important role in supporting and reinforcing the informative and persuasive impact of instructional materials through multimodal strategies - including verbal and visual codes, structured and performative elements, as well as kinesic and paralinguistic features - which prove crucial in motivating students. While there is some debate around the argumentative style of PPT, especially targeting its syntactically deprived, noun-phrase-bullet-point repetitiveness (Tufte 2003), evidence shows that, from the point of view of students, PPT's motivational impact cannot be denied, in terms of both promoting intentions and boosting results (Amare 2006; Kosslyn et al. 2012; Stark and Paravel 2008; Susskind 2005). A number of affordances contribute to the pedagogical efficacy of slideshows, including argumentative immediacy, corporeality of knowledge, modularity, easily transmittable format (Kaplan 2011), as well as the facilitation of pacing and summarizing operations (Lari 2014; Paoletti et al. 2012).

This paper investigates the multi-literacy strategies employed in a corpus of motivational PPT presentations from various universities, aimed at both academic staff (i.e., instructing lecturers on how to motivate students) and at students themselves (i.e., offering advice on how to optimize resources and skills). An integrated methodological framework will be employed, bridging multimodal, critical discourse and genre analysis. As a matter of fact, PPT meaning-making processes stem from a conflation of verbal language (Alley and Neely 2005; Blalock and Montgomery 2005; Burke and James 2008; Paoletti et al. 2012), visual strategies (Clark 2008; Diani 2015; Wysocki 2003, 2007), and bodily communication, such as gesticulation and pointing (Jurado 2015; Knoblauch 2008), all of which make PPT a hybrid genre in academic oratory. As multi-semiotic objects, PPTs will be here investigated from two intertwined perspectives, stemming from Systemic Functional Grammar metafunctions (Halliday 2002, 2004): 
(i) on the ideational level - dealing with the ways in which a visual and textual construct can signify the 'real' world inside its semiotic boundaries, and thus convey extra-linguistic experience (Halliday 2004: 29) - the representation of informative meanings in PPTs will be examined. A typology of the semiotic modes employed in the corpus will single out the referential strategies building a unified image of students' self-confidence and study skill optimisation. Such multimodal analysis will highlight the visually realised aspect of motivation discourse in the corpus, stimulating the following research question: to what extent, and with what effects, does the intersemiotic translation of different modes (Jakobson 1959: 233) shape the ideational component of PPT as a multi-literacy genre in academic discourse?

(ii) on the interpersonal level - dealing with the creation of contact and engagement strategies between a visual and textual construct and its embedded audience, and accounting for the linguistic construction of social relationships (Halliday 2004: 29) - the paper will identify and quantify the most recurrent metadiscursive features employed in order to maximize engagement of both teachers and learners. A typology of the most frequent engagement markers and functions (Hyland 2005: 53-54; Heino, Tervonen and Tommola 2002) will showcase the interactional significance (and verbal realisation) of motivation discourse in the PPT corpus. The following research question will be addressed: how do different realisations of engagement within the instructional community contribute to define the rationale for PPT as a prominent genre in academic communication?

The interaction between the ideational and interactional features of PPT as an academic genre will lastly be explored, following a social semiotic approach to multimodal analysis (Kress and Van Leeuwen 1996, 2001), in order to examine the extent to (and the ways in) which each level contributes in the resemiotization process construing PPT as an example of synoptic/multi-semiotic textuality (Charles and Ventola 2002: 172). 


\section{MATERIALS}

For the purpose of this analysis, a corpus of 32 PPT presentations, recently produced by different universities in 22 countries (including Europe, Africa, China, India, Russia and the USA), has been assembled. The Google search engine (KW: "academic motivation .ppt") has been used in order to retrieve the documents. Given PPT's diffusion as the "most ubiquitous form of digitally assisted demonstration", aimed at a manifold "sociotechnical assemblage" of audiences (Stark and Paravel 2008: 3), and assuming academic motivation to be a complex psycho-social phenomenon (Eccles and Wigfield 2002), an equal number of slideshows targeted to lecturers and to students have been sampled. The former instruct academic staff on how to inspire intentional learners, stimulate commitment to attend class and perform well in exams, while the latter train students to set goals, enhance competence and self-efficacy perception, develop study skills and autonomous behaviour, etc. Two subcorpora have thus been obtained, contrasting symmetric (subcorpus 1) vs. asymmetric (subcorpus 2) communication contexts, totalling 1,213 slides and 56,288 words, as can be seen in Table 1 .

Table 1. Distribution of materials in the corpus.

\begin{tabular}{|l|l|l|}
\hline & Number of slides & Number of words \\
\hline $\begin{array}{l}\text { Subcorpus 1 } \\
\text { (Symmetric) } \\
\text { Staff to staff }\end{array}$ & 744 & 38,254 \\
\hline $\begin{array}{l}\text { Subcorpus 2 } \\
\text { (Asymmetric) } \\
\text { Staff to students }\end{array}$ & 469 & \\
\hline Total & 1,213 & 18,034 \\
\hline
\end{tabular}

\section{METHOD}

This study incorporates socio-visual semiotics and metadiscourse analysis. On the ideational level, a contrastive analysis of the visual communication strategies employed in the corpus will be carried out, highlighting the different semiotic resources employed in PPTs in order to convey referential contents, in both symmetric and asymmetric settings. A multiplicity of visual modes - all of which carrying significant functional load (Tardy 2005: 320) - can be evidenced to interact simultaneously and synergetically 
(Diani 2015: 103) in the corpus. A typology of four semiotic types of visuals will be organised:

a) the numerical mode, i.e., the quantitative presentation of empirical data via mathematical formulae and/or such devices as numerical tables (Bertin 2001; Rowley-Jolivet 2002);

b) the graphical mode, i.e., the presentation of information to be found in graphs, diagrams, maps and other artefacts based on info-graphical strategies (Bertin 2011), aiming at the conceptual framing and synoptic visualization of empirical quantities, so as to display information incidence, evidence, recurrence patterns, etc.;

c) the scriptural or linguistic mode, i.e., the presentation of information using written verbal language (Rowley-Jolivet 2000, 2002), pivoting on the linguistic and argumentative construction of information;

d) the figurative mode, i.e., the presentation of information using visual artefacts such as photographs, images, webpages, etc. (Rowley-Jolivet 2002, 2004), which hinge on allusive and affective symbolizations of empirical reality, so as to elicit emotional responses on the part of the viewer.

It should be noted that (a) and (b) are monosemic modes, in that, by referring to empirical quantities in extra-linguistic reality, the meaning of every sign is defined beforehand, and known prior to (and regardless of) any "observation of the collection of signs" (Bertin 2011:2). While both mathematics and graphics display high adherence to empirical phenomena, i.e., they generally tend to be perceived as unambiguous, objective, neutral and non-culture driven, they differ as to their perceptual structure, for graphics visually provides instantaneous perception to quantitative phenomena which would otherwise require longer processing. In the light of this, it is possible to explain today's growing need for the visualization of data and information (Friendly 2009; Tufte 2001). (C) and (d) are instead polysemic modes, because "the meaning of the individual sign follows and is deduced from consideration of the collection of signs", so that "signification becomes subjective and thus debatable" (Bertin 2011: 2). 
Although the difference between written language and figurative imagery largely amounts to their appeal to different sensory stimuli (hearing and sight), and to the different referential and social interactions strategies they employ, both are perceived as being on the opposite side of the referential spectrum from mathematics and graphics, as they tend to be considered subjective, biased and culture driven. Although social semiotics has fully clarified that visual language works on a lexicogrammar of its own, realizing meanings as linguistic structures do (Kress 2003, 2010; Kress and Van Leeuwen 1996, 2001; Van Leeuwen 2004, 2005), and that no human (re)presentation of extra-linguistic reality is ever without cognitive effects, such perception may have an explanation. As a matter of fact, while numerical and graphical visuals tend to naturalize the distance between their semiotic boundaries and the reality they - as signs - stand for, the scriptural and figurative modes tend to emphasize such hiatus, and to display their "rich cultural load" (Rowley-Jolivet 2000: 4), since in the case of polysemic codes, the "reading operation takes place between the sign and its meaning", whereby ambiguity and subjectivity are brought in the process (Bertin 2011: 2). Reading pictures, as well as reading words, actually involves not only construing meanings from what we see/read, but also from what we know (Kostelnick 1993: 244), which makes both operations overtly cognitive in nature. Figure 1 offers a schematization of the semiotic modes along the (perceived) referential continuum.

\begin{tabular}{|c|c|}
\hline $\begin{array}{l}\text { (perceived as) objective/ } \\
\text { non-culture driven }\end{array}$ & $\begin{array}{r}\text { (perceived as) subjective/ } \\
\text { culture driven }\end{array}$ \\
\hline$\underbrace{\prime}$ & $\underbrace{\prime}$ \\
\hline $\begin{array}{l}\text { NUMERICAL GRAPHICAL } \\
\text { monosemic }\end{array}$ & $\begin{array}{l}\text { SCRIPTURAL FIGURATIVE } \\
\text { polysemic }\end{array}$ \\
\hline
\end{tabular}

Figure 1. The four semiotic modes along the referential continuum.

The present analysis will account for the proportions, functions and variation patterns of numerical, graphical, scriptural and figurative slides in both PPT subcorpora. The cognitive interplay among all types can, as a matter of fact, provide an ideational picture of PPT as an integration code (Kress and Van Leeuwen 2004) hinging on semiotic spanning processes among concurrent co-textual modes (Charles and Ventola 2002). 
On the interpersonal level, a microscopic bottom-up linguistic analysis will be carried out - within the scriptural slides of both PPT subcorpora - in order to identify and quantify the most recurrent interaction-oriented metadiscourse features creating engagement effects with readers/viewers. A typology of engagement markers (Hyland 2005: 53-54; Heino, Tommola and Tervonen 2002; Vassileva 2002; Webber 2002, 2005) will be organised and discussed, accounting for the verbal realizations of motivation discourse:

a) READER PRONOUNS (you, your, yourself), i.e., direct appeals to the audience embedded in presentations, which are highly expected to develop a sense of meanings being specifically produced for them;

b) COMMUNity PRONOUNS (inclusive we, our, ourselves), i.e., appeals to an integrated educational community, in which a sense of togetherness and commonality is built;

c) QUESTIONS, i.e., structures positing meanings interrogatively rather than assertively, covering doubts the audience may have on specific aspects, suggesting or anticipating a cognitive gap that the presentation will deal with, signalling "queries in need of reply, interpretation, and conclusion" (Soler 2007: 100);

d) IMPERATIVES, i.e., directive structures conveying do's and don'ts to be implemented;

e) Obligation, or compulsion, modals (should, must, have to, need to), i.e., modals implying "to a greater or lesser extent, that the speaker is advocating a certain form of behaviour" from the part of the audience (Quirk and Greenbaum 1990/2008: 68).

The proportions, functions and variation patterns among the five types of engagement markers and between the subcorpora will be discussed, in order to evidence the ways in which two different segments of a discourse community are targeted by specific interactional resources and pragmatic strategies. 


\section{RESULTS}

\section{IV.1. Ideational level}

Table 2 provides a breakdown of the semiotic types of slides (numerical, graphical, scriptural and figurative) to be found in each PPT presentation, and in each subcorpus.

Table 2. Semiotic modes in PPT presentations: variations between subcorpora

\begin{tabular}{|c|c|c|c|c|c|c|}
\hline PPT & No. SLIDES & AVG. & NUMERICAL & GRAPHICAL & SCRIPTURAL & FIGURATIVE \\
\hline \multicolumn{7}{|c|}{ SUBCORPUS 1: symmetric context (staff to staff) } \\
\hline 01 & 29 & \multirow{16}{*}{46,5} & 3 & 1 & 25 & 0 \\
\hline 02 & 48 & & 5 & 7 & 35 & 1 \\
\hline 03 & 35 & & 0 & 3 & 18 & 14 \\
\hline 04 & 40 & & 0 & 9 & 30 & 1 \\
\hline 05 & 25 & & 2 & 2 & 21 & 0 \\
\hline 06 & 26 & & 3 & 5 & 18 & 0 \\
\hline 07 & 48 & & 0 & 0 & 45 & 3 \\
\hline 08 & 24 & & 0 & 2 & 18 & 4 \\
\hline 09 & 35 & & 0 & 1 & 33 & 1 \\
\hline 10 & 28 & & 0 & 2 & 25 & 0 \\
\hline 11 & 65 & & 0 & 3 & 58 & 4 \\
\hline 12 & 18 & & 0 & 1 & 17 & 0 \\
\hline 13 & 72 & & 0 & 28 & 41 & 3 \\
\hline 14 & 21 & & 0 & 0 & 21 & 0 \\
\hline 15 & 102 & & 0 & 1 & 86 & 15 \\
\hline 16 & 128 & & 0 & 4 & 105 & 19 \\
\hline \multicolumn{3}{|c|}{ Tot. SUBCORPUS1: $\mathbf{7 4 4}$} & $\mathbf{1 3}(1,8 \%)$ & $69(9,3 \%)$ & $596(80,1 \%)$ & $\mathbf{6 5}(8,8 \%)$ \\
\hline \multicolumn{7}{|c|}{ SUBCORPUS 2: asymmetric context (staff to students) } \\
\hline 17 & 61 & \multirow{16}{*}{29,3} & 0 & 7 & 18 & 36 \\
\hline 18 & 24 & & 0 & 2 & 18 & 4 \\
\hline 19 & 28 & & 0 & 0 & 11 & 17 \\
\hline 20 & 21 & & 0 & 0 & 21 & 0 \\
\hline 21 & 28 & & 0 & 2 & 25 & 1 \\
\hline 22 & 37 & & 0 & 0 & 10 & 17 \\
\hline 23 & 34 & & 0 & 3 & 23 & 8 \\
\hline 24 & 9 & & 0 & 0 & 5 & 4 \\
\hline 25 & 20 & & 2 & 4 & 14 & 0 \\
\hline 26 & 22 & & 0 & 1 & 19 & 2 \\
\hline 27 & 25 & & 1 & 0 & 16 & 8 \\
\hline 28 & 25 & & 0 & 7 & 10 & 8 \\
\hline 29 & 21 & & 0 & 0 & 16 & 5 \\
\hline 30 & 15 & & 0 & 0 & 8 & 7 \\
\hline 21 & 42 & & 0 & 22 & 20 & 0 \\
\hline 32 & 57 & & 0 & 6 & 49 & 2 \\
\hline \multicolumn{3}{|c|}{ Tot. SUBCORPUS 2: $\mathbf{4 6 9}$} & $\mathbf{3}(0,7 \%)$ & $54(11,5 \%)$ & $283(60,4 \%)$ & $119(25,4 \%)$ \\
\hline
\end{tabular}


The typology has been organized following the referential continuum in Figure 1. Beside the disparity in the total (744 vs. 469), and in the average number of slides (46,5 vs. 29,3 ) in the subcorpora - which could be explained in terms of the different attention span and literacy standards to be expected from an expert $v s$. student audience - the table evidences some remarkable variations among the semiotic modes.

Numerical slides, presenting empirical reality via quantitative tables and formulae, seldom occur in both subcorpora (1,8\% in subcorpus 1 and $0,7 \%$ in subcorpus 2$)$. Their typical function is to provide figures as empirical, or scientific, evidence to what is being discussed in the presentation, as is shown for instance in Figure 2 (Williams 2013, from subcorpus 1), informing lecturers about the statistical significance of typical operant conditioning measures. Given that the pragmatic purpose of the PPT corpus in consideration is to motivate people, whatever their role in the educational process, it is not surprising that numerical slides should appear as the least frequent mode: as a highly discipline-specific type of visual, they can perform gate-keeping functions with respect to the lay audience, thus producing ostracism and exclusion effects (Kostelnick 1993: 250).

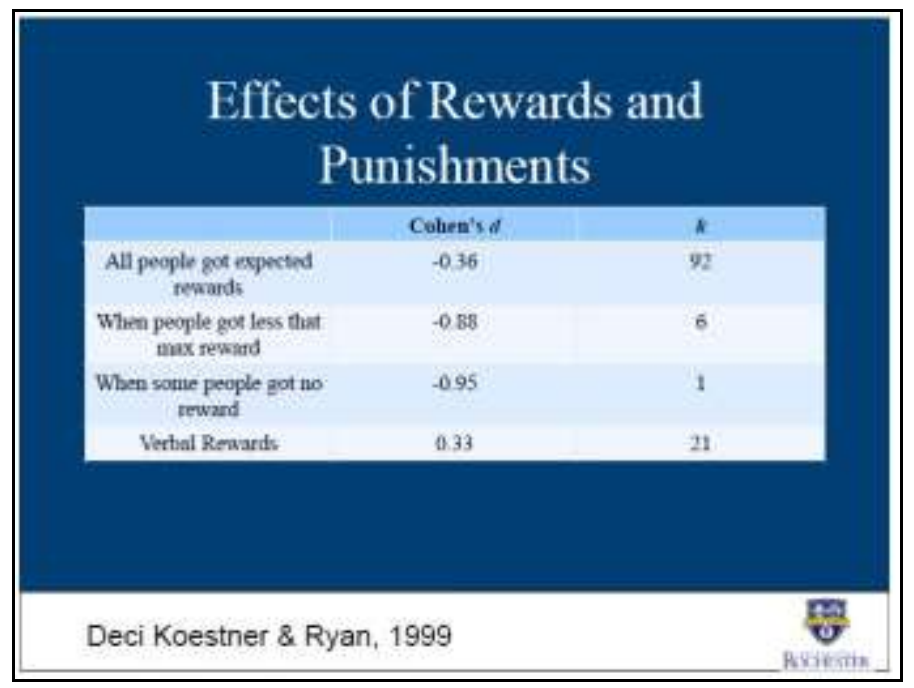

Figure 2. Numerical slide (Williams 2013)

A fairly similar trend is shown in both subcorpora by another token of highly specialized visual communication: amounting to $9,3 \%$ of subcorpus 1 and $11,5 \%$ of subcorpus 2 , graphical slides are represented by diagrams, charts, maps and other data visualization devices, which present extra-linguistic reality by means of picturing relevant numerical 
quantities. Although the graphical portrayal of quantitative information may be perceived as an epistemologically neutral operation, one which does not interfere with the objective rendering of reality as it is, outside of any semiotic system, this is merely the effect of epistemic and social naturalization. A graph, for instance, is designed in order to show evidence, emphasize relevance of information, frame significant data, etc. Despite its monosemic character, it is in itself a cognitive operation, entailing a certain degree of interpretation of extra-textual reality. The reading of empirical data through patterns is easier to perceive in visual rather than in numerical (or textual) form, because of the highly informative - and claim-making - potential of info-graphical compositional knowledge. This makes the graphical mode an optimal resource for the coding of topological meanings in computational terms (Rowley-Jolivet 2000: 6), and a most effective strategy in discipline-oriented professional visualization, one that is also deeply linked to the epistemology of the disciplinary field in which such visuals are produced (ibid.). In both PPT subcorpora under examination, graphical slides have this function, as can be seen in Figure 3 (Mertz 2013). This graphical slide from subcorpus 2 shows students how to develop leadership skills by visualizing the quantitative relationship between task- (or individual-)focused behaviour and social (or supportive) behaviour.

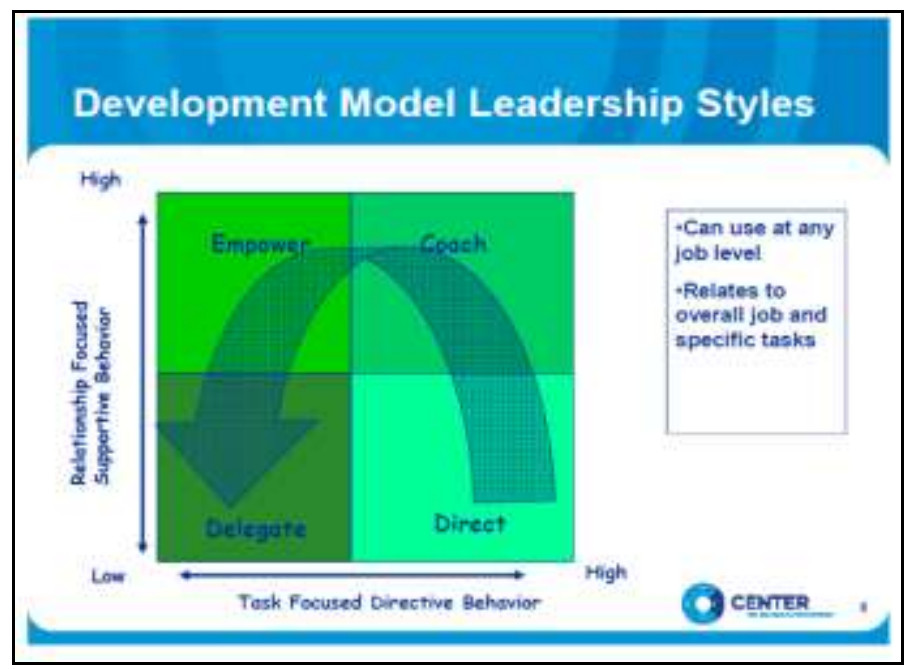

Figure 3. Graphical slide (Mertz 2013)

Opposite trends are instead shown by the two most frequent semiotic modes in both subcorpora, namely, the polysemic ones: linguistic slides amount to $80,1 \%$ of subcorpus 
1 vs. $60,4 \%$ of subcorpus 2 , while figurative slides represent $8,8 \%$ of subcorpus 1 vs. $25,4 \%$ in subcorpus 2 . A closer look at the data reveals that approximately twice as many scriptural slides can be found in subcorpus 1 (596) than in subcorpus 2 (283), while the reverse applies to figurative slides (119 in subcorpus 2 vs. 65 in subcorpus 1). This seems to suggest that in staff-to-staff presentations, when it comes to the preferred strategy for structuring ideational contents, especially when typological meanings are involved, words are expected to be more effective than pictures: that is, when targeting the logical and argumentative competence of academic staff, the verbal and linguistic construction of information prevails, as can for instance be inferred from Figure 4 (Wood 2017, from subcorpus 1), explaining a researcher's key findings in psychocognitive pedagogy.

\section{Key findings:}

I found that students' perceptions of teacher-student relationship quality had am impact upon the development and enactment of student autonomy.

The mediating variable was the teacher's ability (through their behaviours and methods) that had a positive influence upon an individual student's perceived competence.

My school-based focus was upon inquiry-based leaming in science. Other methods focused upon students' motivation and engagement with their schooling in general (regardless of curriculum subject).

Figure 4. Scriptural slide (Wood 2017)

Conversely, the dominant mode in asymmetric presentations is the allusive, affective and persuasive representation of polysemic visuals. Figurative language is preferred when an emotional response - which is at the foundation of self-motivation processes (Clark 2003) - is being elicited, as can be inferred from Figure 5 (Salama 2014, from subcorpus 2), featuring a portrait of what motivation and team work may look like, in the shape of an inspiring illustration of social-supportive behaviour. Being endowed with a high degree of iconicity, i.e., a complex referential load, which makes signification a subjectively biased operation, calling for disambiguation from the part of the viewer in order to be fully understood, figurative imagery pivots on the emotional response of the 
audience, who is engaged in complementing the allusive stimuli offered by the visuals with personal meanings. For this reason, figurative visuals are typical of advertising language, for their main function is a persuasive one (Rowley-Jolivet 2002: 30). On the contrary, specialized visuals such as graphical devices, which are typical of scientific language, have a highly eidetic potential, i.e., they are endowed with predetermined discipline-specific informational meanings, which are required for such visuals to be understood at all. While graphical visuals are monosemic, eidetic and stylised, and perform an informative and argumentative function, figurative visuals are polysemic, iconic and allusive, and have a persuasive and promotional function.

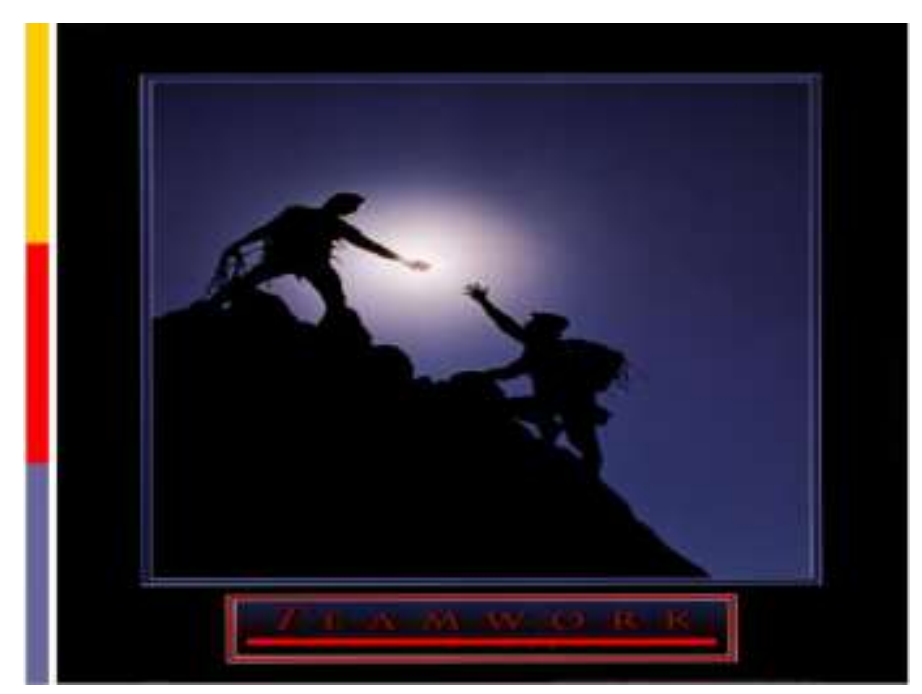

Figure 5. Figurative slide (Salama, 2014)

The proportions of figurative and linguistic slides within each PPT subcorpus can be further observed in Charts 1 and 2. Symmetric contexts display nearly the same amount of graphical and figurative slides, while the figurative $v s$. scriptural ratio is nearly 1:10 (see Chart 1). In asymmetric contexts, there are twice as many figurative than graphical slides, while the figurative $v s$. scriptural increases to approximately 1:2 (see Chart 2). 


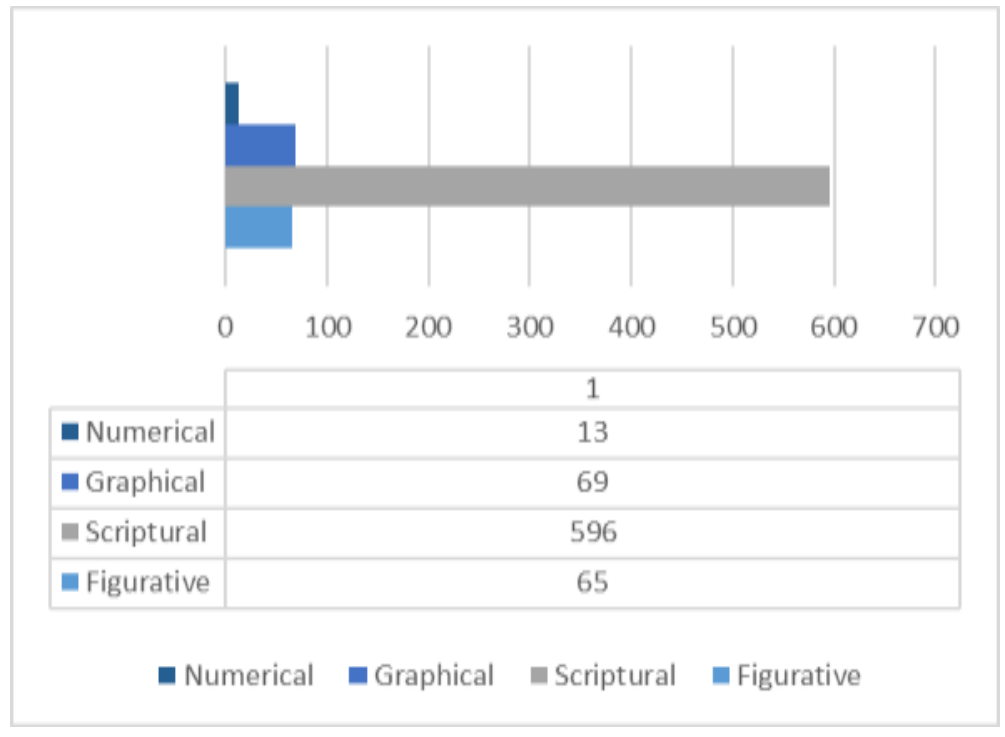

Chart 1. Semiotic modes in subcorpus 1

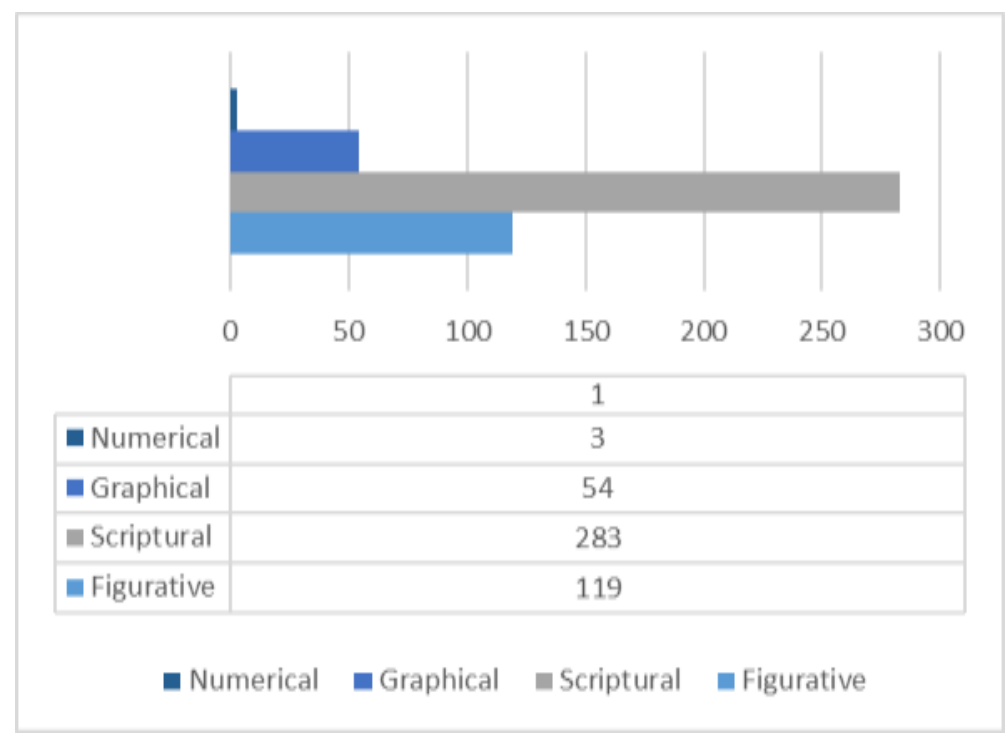

Chart 2. Semiotic modes in subcorpus 2

With respect to such tendencies, it can be observed that different pragmatic functions are associated with the discursive modes of the subcorpora (Sala 2008: 16). This appears to be a more convincing explanation than the alleged objectivity of verbal language $v s$. the subjective bias of visual language. Being targeted to the verbal literacy skills expected from academic staff, the PPT presentations in subcorpus 1 obey a predominantly informativeand argumentative function, as can easily be expected in expert-to-expert 
disciplinary communication, where "knowledge production is carried out and codified" in writing (Berkenkotter and Huckin 1995: 1). On the contrary, addressing the visual literacy skills of students, and being meant to elicit a psychological response from them as a trigger to better self-management strategies, the presentations in subcorpus 2 exploit the attractiveness of visual display and obey a persuasive and promotional function.

Both discursive modes - the verbal/argumentative and the visual/persuasive - are reflected in the rationale for PPT as a leading academic genre, in both research and instructional settings. On the one hand, in symmetric contexts, the cognitive architecture and impact of what is considered the most typical "conferencing product" (Campagna 2009: 387) is granted by the functional collaboration between verbal (i.e., running text) and visual discourse formulations (i.e., use of visuals, formatting devices, etc.; Virbel et al. 1999: 35). The synchronous visual-cum-verbal progression (Rowley-Jolivet 2000: 13 ) is as a matter of fact perceived and decoded as an integrated whole by the audience. Conversely, in asymmetric contexts, the multi-literacy stimuli offered by PPT can be said to be effective as concerns the transfer of contents from experts to learners: evidence from social and behavioural sciences (Kosslyn et al. 2012; Paoletti et al. 2012) shows that PPT's conflation of lexico-syntactical and visual structures tends to be preferred by students over traditional media (such as blackboards or transparencies), in that it facilitates and strengthens information processing operations, to such an extent that students tend to tag themselves as "visual learners" (Amare 2006: 302). By stimulating the perception and retention of materials, PPT textuality both enhances students' self-efficacy beliefs (Susskind 2005: 211) and boosts their motivation towards learning (Corbeil 2007; Ilter 2009; Lari 2014; Oommen 2012; Wang 2011). Interestingly, motivation seems to emerge from the investigated PPT corpus as a psychosocial outcome of multi-semiotic textuality.

\section{IV.2. Interpersonal level}

Table 3 provides a breakdown of the most recurrent metadiscursive resources to be found in the linguistic slides of both subcorpora, and meant to elicit engagement and commitment from the part of the audience embedded in PPT presentations. Data are presented in normalized figures (per 10,000 words). It can clearly be seen that there is a 
much higher frequency of engagement markers in subcorpus 2 than in subcorpus 1 $(542,86$ vs. 325,97). Although, as shown in Table 2, subcorpus 2 has approximately half as many scriptural slides as subcorpus 1 ( $283 v s .596)$, the average frequency of markers in scriptural slides is over twice as high in subcorpus $2(45,23)$ than in subcorpus 1 (20,37). Motivational discourse addressing students seems in fact more in need of specific linguistic resources in order to signal the inclusion of readers as discourse participants, emphasising on the one hand commonality - as is the case of the inclusive pronouns we, us, our, ourselves - and on the other the individuality of each reader/viewer, who needs to be constantly made aware (by means of reader pronouns such as you, your, yourself) of being the presentation's designed addressee and beneficiary.

Table 3. Engagement markers in PPT presentations (normalized frequency per 10,000 words): variations between subcorpora

\begin{tabular}{|c|c|c|c|c|c|c|c|}
\hline PPT & $\begin{array}{l}\text { No. } \\
\text { ENGAGEMENT } \\
\text { MARKERS }\end{array}$ & AVG. & $\begin{array}{l}\text { READER } \\
\text { PRONOUNS } \\
\text { (you, your, } \\
\text { yourself) }\end{array}$ & $\begin{array}{l}\text { COMMUNITY } \\
\text { PRONOUNS } \\
\text { (we, us, our, } \\
\text { ourselves) }\end{array}$ & QUESTIONS & IMPERATIVES & $\begin{array}{l}\text { OBLIGATION } \\
\text { MODALS } \\
\text { (should, must, } \\
\text { have to, need } \\
\text { to) }\end{array}$ \\
\hline \multicolumn{8}{|c|}{ SUBCORPUS 1: symmetric context (staff to staff) } \\
\hline 01 & 3,66 & \multirow{16}{*}{20,37} & 0 & 2,35 & 1,04 & 0 & 0,26 \\
\hline 02 & 3,92 & & 0,26 & 1,82 & 1,04 & 0 & 0,78 \\
\hline 03 & 16,99 & & 3,66 & 0,26 & 6,53 & 6,53 & 0 \\
\hline 04 & 4,44 & & 1,56 & 0,26 & 2,61 & 0 & 0 \\
\hline 05 & 7,05 & & 0,26 & 0 & 6,79 & 0 & 0 \\
\hline 06 & 9,41 & & 0,26 & 0 & 0,78 & 7,58 & 0,78 \\
\hline 07 & 44,7 & & 9,14 & 1,04 & 1,82 & 32,67 & 0 \\
\hline 08 & 10,19 & & 1,82 & 0,52 & 0,78 & 6,79 & 0,26 \\
\hline 09 & 12,80 & & 2,35 & 0 & 2,61 & 7,05 & 0,78 \\
\hline 10 & 7,05 & & 3,39 & 2,35 & 1,3 & 0 & 0 \\
\hline 11 & 60,64 & & 27,97 & 4,44 & 8,88 & 18,82 & 0,52 \\
\hline 12 & 12,28 & & 5,48 & 2,09 & 1,3 & 3,39 & 0 \\
\hline 13 & 6,79 & & 0,26 & 0 & 6,53 & 0 & 0 \\
\hline 14 & 3,92 & & 0 & 0 & 0 & 2,35 & 1,56 \\
\hline 15 & 48,88 & & 10,19 & 2,09 & 14,37 & 20,91 & 1,30 \\
\hline 16 & 73,19 & & 23 & 14,37 & 17,51 & 17,25 & 1,04 \\
\hline \multicolumn{3}{|c|}{ Tot. SUBCORPUS 1: 325,97 } & 89,66 & 31,63 & 73,97 & 123,38 & 7,32 \\
\hline
\end{tabular}




\begin{tabular}{|c|c|c|c|c|c|c|c|}
\hline \multicolumn{8}{|c|}{ SUBCORPUS 2: asymmetric context (staff to students) } \\
\hline 17 & 28,27 & \multirow{16}{*}{45,23} & 8,87 & 0,55 & 10,53 & 8,31 & 0 \\
\hline 18 & 49,35 & & 28,27 & 1,66 & 13,3 & 5,5 & 0,55 \\
\hline 19 & 37,7 & & 15,52 & 0 & 2,21 & 18,85 & 1,1 \\
\hline 20 & 12,75 & & 6,65 & 2,21 & 3,88 & 0 & 0 \\
\hline 21 & 75,41 & & 19,4 & 1,66 & 23,28 & 23,84 & 7,2 \\
\hline 22 & 42,69 & & 28,83 & 3,88 & 1,66 & 8,31 & 0 \\
\hline 23 & 21,62 & & 9,42 & 1,1 & 1,1 & 9,98 & 0 \\
\hline 24 & 28,27 & & 18,29 & 0,55 & 0,55 & 7,76 & 1,1 \\
\hline 25 & 29,38 & & 16,63 & 0,55 & 7,76 & 4,43 & 0 \\
\hline 26 & 29,38 & & 13,3 & 1,1 & 7,76 & 7,2 & 0 \\
\hline 27 & 8,87 & & 7,2 & 0 & 1,66 & 0 & 0 \\
\hline 28 & 8,87 & & 2,21 & 0 & 0,55 & 5,5 & 0,55 \\
\hline 29 & 32,16 & & 14,41 & 2,77 & 3,88 & 9,98 & 1,1 \\
\hline 30 & 63,76 & & 34,93 & 13,86 & 5,5 & 8,87 & 0,55 \\
\hline 31 & 14,97 & & 6,09 & 1,1 & 6,65 & 1,1 & 0 \\
\hline 32 & 59,33 & & 13,3 & 3,32 & 12,19 & 25,5 & 4,99 \\
\hline \multicolumn{3}{|c|}{ Tot. SUBCORPUS 2: $\mathbf{5 4 2 , 8 6}$} & 243,43 & 34,38 & 102,58 & 145,28 & 17,19 \\
\hline
\end{tabular}

The preferred interactional features in both subcorpora are reader pronouns and imperatives, albeit in inverted proportions. While imperatives are the most widely used category in subcorpus $1(123,38)$, followed by reader pronouns $(89,66)$, reader pronouns rank first in subcorpus $2(243,43)$, followed by imperatives $(145,28)$. The proportions within each subcorpus can be further observed in Charts 3 and 4. Symmetric contexts show a you vs. we ratio of 3:1, while the imperative vs. you ratio is approximately 4:3 (see Chart 3); in asymmetric contexts, the you vs. we ratio increases to 7:1, while the imperative vs. you ratio declines to $3: 5$ (see Chart 4). This seems to indicate that community pronouns, emphasising common knowledge or experience, or advocating team spirit (Vassileva 2002: 270), are a favourite interactional resource when motivation discourse is meant for academic staff, whereas reader pronouns, stressing individual worth and thus boosting individual effort, are a typical resource when students are being addressed. 


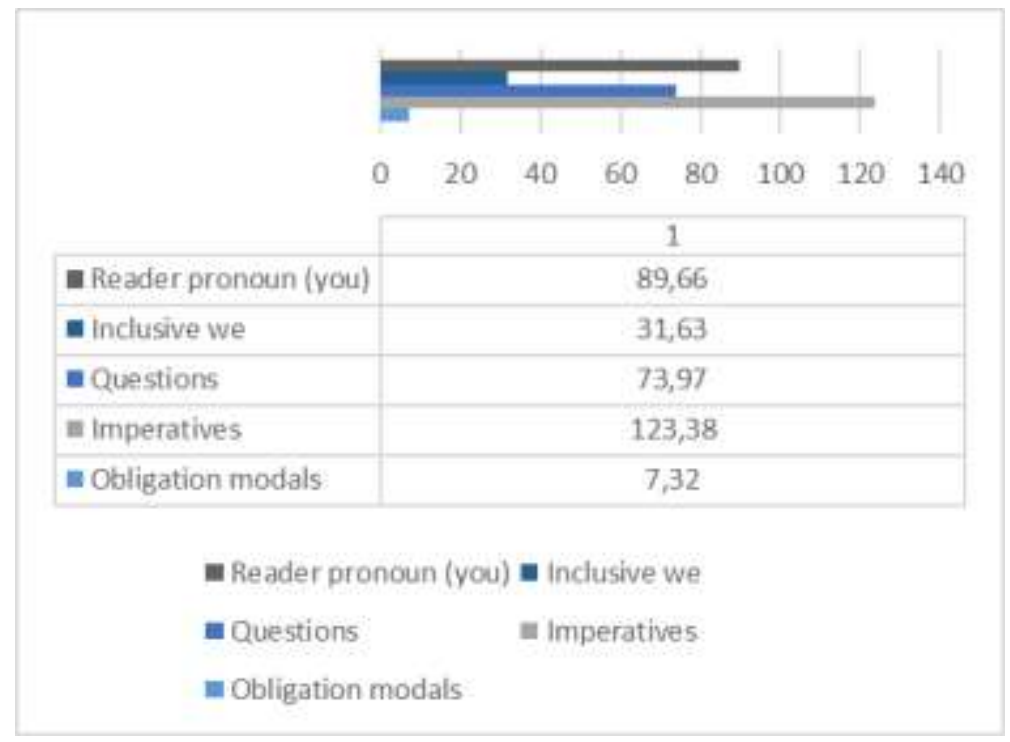

Chart 3. Engagement markers in subcorpus 1 (normalized frequency per 10,000 words)

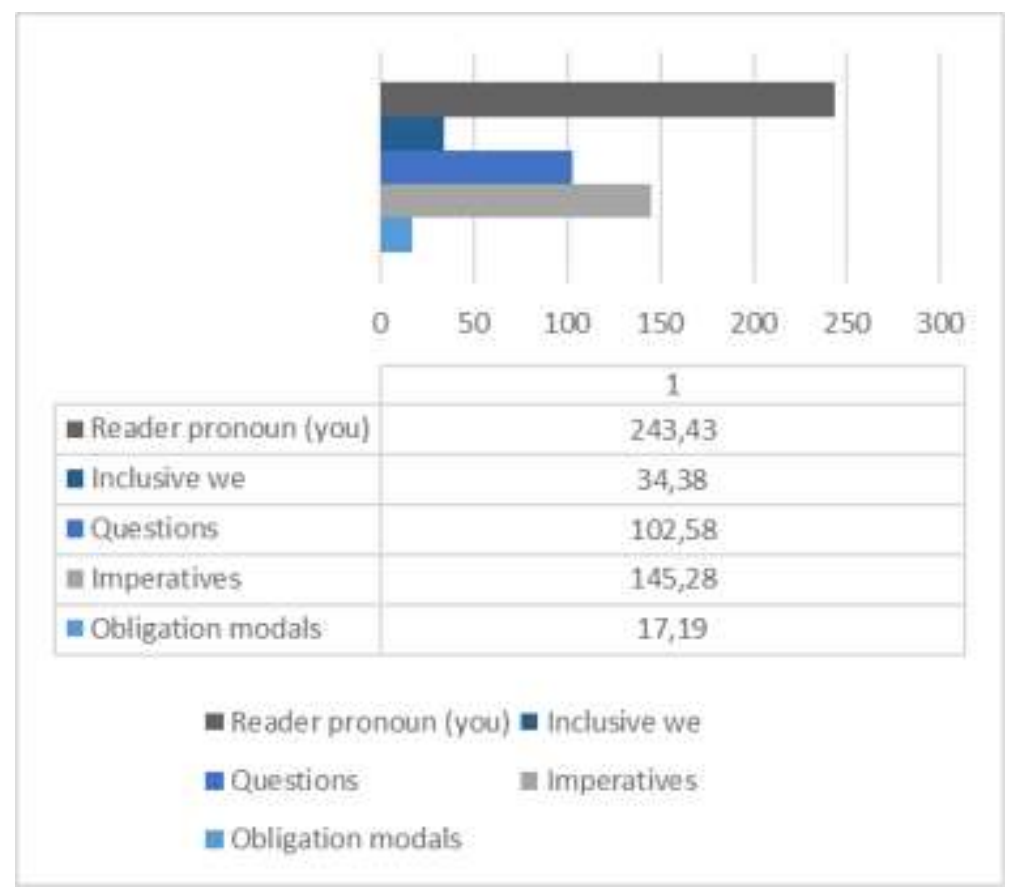

Chart 4. Engagement markers in subcorpus 2 (normalized frequency per 10,000 words)

The charts also reveal information about the third preferred resource for engagement in the PPT corpus, i.e., questions. While asymmetric contexts use way less than half as many questions as reader pronouns $(102,58$ vs. 243,43), in symmetric contexts the proportion significantly changes to approximately four interrogative structures every five reader pronouns $(73,97$ vs. 89,66). Questions are typical of PPT's conventionalized 
cognitive style (Tufte 2003), and of PPT as an "open-for-discussion" tool (Webber 2002) for communicating state-of-the-art knowledge to an audience who is expected to react, either asking questions or producing comments. As can be seen in Figure 6 (Landis 2005, from subcorpus 1), the typical PPT slide follows an add-on, theme-rheme (or gap-filler) information sequence, eliciting the reader/viewer's curiosity via the heading, and providing answers in the body text (usually organized through bullet points). If slides in general are organized in gap-filler slots, in the case of subcorpus 1 this seems to match the possible informational request of an expert audience, who, being engaged by a possible gap in their knowledge system, will probably look forward to developing new educational protocols. In the case of a student audience, instead, PPT's argumentative structure tends to be perceived as facilitating the understanding and retention of instructional materials (Susskind 2005: 204). In both contexts, the use of interrogative structures can be said to function as an interactional booster of standard PPT gap-filler argumentative patterns.

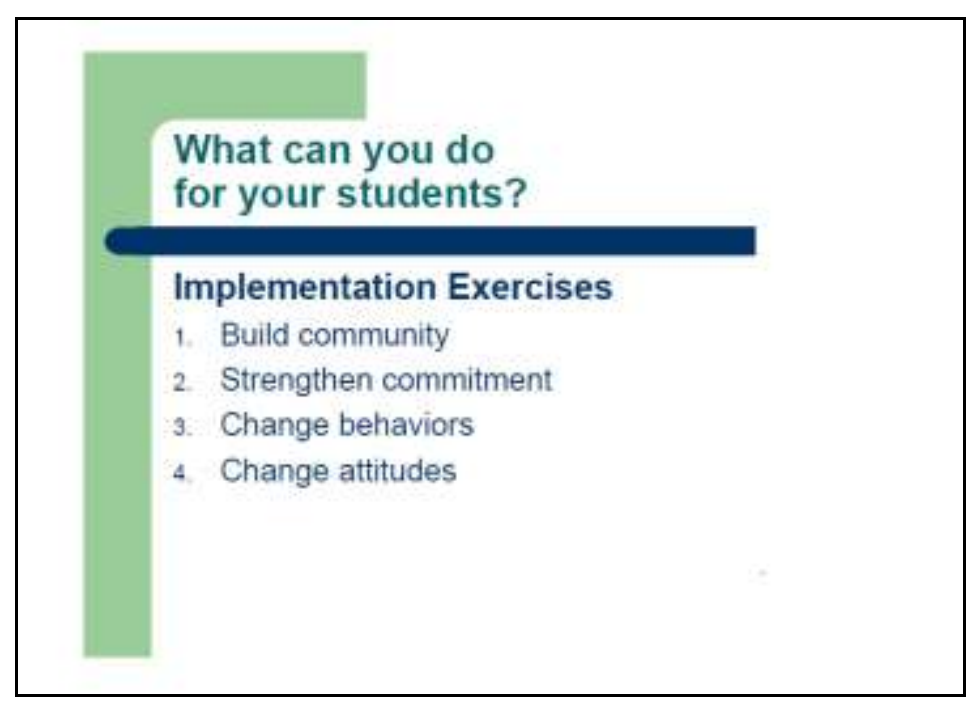

Figure 6. Typical question slide (Landis 2005)

Overall, results on the interpersonal level seem to confirm that different engagement strategies are needed in different communicative situations. The behaviour of imperatives and questions in the subcorpora seems in particular to substantiate what was hypothesized at the ideational level (cf. IV.1 above). Metadiscursive resources 
complement the verbal and argumentative tenor of subcorpus 1 with explanatory and normative features: as a matter of fact, symmetric presentations frequently anticipate and clarify possible cognitive gaps from the part of lecturers, as well as establish the do's and don'ts of motivating students. Questions and imperatives are not perceived here as Face Threatening Acts (Goffman 1967), for subcorpus 1 addresses a professional audience, expecting explicit instructions and caveats from PPTs. The visual and persuasive tenor of subcorpus 2, on the contrary, needs differently cogent interactional resources, for its purpose is to enthuse individuals to commit to volitional learning - which involves the massive use of reader pronouns and of figurative imagery (as shown in IV.1). Imperatives also frequently occur in subcorpus 2. Here, however, directives tend to be packaged in specific argumentative sections within each PPT presentation (as can be seen in Figure 7, Holmes 2013, from subcorpus 2), do's and don'ts sections which students may decide not to access in case they do not wish to take specific advice. Such strategic hedging of imperatives in subcorpus 2 contributes to dismantle the face-threatening potential of directives, while keeping the potential benefits of instructional discourse active

\section{CONCLUDING REMARKS}

By bridging socio-visual semiotics and metadiscourse analysis, this study has investigated the ideational and interpersonal strategies structuring PPT as a resourceful genre for the implementation of motivation strategies in academic environments. Results from multimodal analysis have shown, on the ideational level, that the construction of informative meanings in PPTs hinges on the intersemiotic translation of different modes (Jakobson 1959: 233), i.e., the interaction and integration of the numerical, graphical, scriptural, and figurative mode. The coexistence of four semiotic systems, interacting with one another along the referential continuum and activating across different pragmatic purposes and communicative settings, construes PPT as an integration code among a plurality of literacy practices, combining and synergizing monosemic and polysemic systems of signification (Kress and Van Leeuwen 2001). A synoptic screen genre (Charles and Ventola 2002: 172), the PPT slideshow is characterized by a combination of multi-semiotic resources constituting a whole and 
coherent communicative act (Degano 2012), both in research and pedagogical settings. Meaning-making processes are distributed, and constantly resemiotized (Iedema 2001), across all modes, accommodating flexible functional variation patterns, as evidenced by the contrastive analysis between the subcorpora. The flexibility with which each semiotic mode can modulate itself within the same communicative event suggests PPT as a hybrid "inscribed genre", that is, a mainly (albeit not exclusively) written genre combining "language, image, and graphics in an integrated whole" (Van Leeuwen 2004: $10)$.

Such hybridity explains PPT's efficacy in academic discourse, with respect to both informative and argumentative (Diani 2015) and persuasive and promotional functions (Busà 2010). In this respect, results on the ideational level seem to confirm - in line with (and in the light of) recent linguistic and psycho-pedagogical research (BellésFortuño and Ollero 2015; Bellés-Calvera and Bellés-Fortuño 2018; Dörnyei 2001) that PPT may positively influence students' task-focused and social supportive behaviour. Both effects can impact the building of a unified image of self-confidence, and the optimisation of students' study skills and general organisation. Motivation seems therefore to be an interestingly psycho-social and discursive phenomenon.

Results from metadiscourse analysis (and on the interpersonal level) have shown how motivational PPTs hinge on a typology of interactional markers - namely, reader and community pronouns, imperatives, and questions - whose function is to maximize engagement and commitment from the part of both teachers and learners. Engagement markers are the main linguistic manifestation of motivation discourse in the PPT corpus, and, as in the case of the abovementioned four semiotic modes, they also evidence functional variation patterns along different pragmatic purposes and communicative contexts. Interactional outcomes of motivation discourse can encompass a range of functions, from explanatory to normative to emotional ones, depending on the proportions among the various types of metadiscourse used in the subcorpora, and complementing the argumentative efficacy of PPT as a leading genre in academic contexts. The case of questions and imperatives seems in particular to highlight the high potential for dialogical communication, and for the eliciting of various degrees of commitment on the part of the reader, which is typical of PPT's standard logical structure, usually built on gap-filler (or theme-theme) information sequences. Reader 
and community pronouns also seem a typical resource of PPT as a hybrid "inscribed genre" (Van Leeuwen 2004: 10), whereby repeated appeals to individual readers and the pedagogical community - also crucial in the process of motivating both oneself and others - are accommodated by the multi-semiotic affordances of the genre.

In conclusion, this paper has aimed to suggest that the motivational impact of PPT in a constructivist academic environment can be found at both the ideational and the interpersonal level. It is distributed across four signification systems, stemming in different ways from the ideational expression of empirical experience offered by various types of visuals (such as, for instance, graphical devices and/or figurative imagery), as well as from the linguistic construction of dialogical roles between academic staff and students in the communication of experiential meanings (as is the case of metadiscourse markers). Multimodal literacy can therefore contribute, on the one hand, to the development of committed, autonomous and creative behaviour on the part of individual students, and, on the other, to the reinforcement of social processes of "communication and collaboration among students" as well as between students and teachers (Bellés-Calvera and Bellés-Fortuño 2018: 107). In the light of the above, potential implications of the present study may include extending the analysis to the third metafunction Systemic Functional Grammar metafunction (Halliday 2002, 2004). Researching PPT as a fully trifunctional language may help further research focus on the ways - also including "performative" aspects of PPT, such as kinesic and paralinguistic features (Van Leeuwen 2004: 10) - in which the trifunctional load is worked out among the different resources in the multi-semiotic mix.

\section{REFERENCES}

Alley, M. and Neeley, K.A. 2005. "Rethinking the design of presentation slides: A case for sentences headlines and visual evidence". Technical Communication, 52 (4), 417-427.

Amare, N. 2006. "To slideware or not to slideware: Students' experiences with Powerpoint vs. lecture". Journal of Technical Writing and Communication, 36 (3), 297-308. 
Bellés-Calvera, L. and Bellés-Fortuño, B. 2018. "Written Corrective Feedback with Online Tools in the Medicine Classroom: Bombay TV”. In López-García, C. and Manso, J. (Eds.), Transforming Education for a Changing World. Eindhoven, NL: Adaya Press, 106-199. 4 August 2018. http://www.adayapress.com/wpcontent/uploads/2017/07/CTED11.pdf

Bellés-Fortuño, B. and Ollero, N. 2015. "Motivation: A key to success in the foreign language classroom? A case study on vocational training and higher education English courses”. DOI: http://dx.doi.org/10.4995/HEAd15.2015.431

Berkenkotter, C. and Huckin, T.N. 1995. Genre Knowledge in Disciplinary Communication. Hillsdale, NJ: Lawrence Erlbaum Associates.

Bertin, J. 1973. Semiologie graphique: Les diagrammes, les réseaux, les cartes. Engl. transl. Semiology of Graphics: Diagrams, Networks, Maps. Madison: University of Wisconsin Press.

- 2011. Graphics and Graphic Information Processing. Berlin: De Gruyter.

Bhatia, V.J. 2004. Worlds of Written Discourse: A Genre-Based View. London: Continuum.

Blalock, M.G. and Montgomery, R.D. 2005. "The effect of PowerPoint on student performance in principles of economics: An exploratory study". Journal for Economics Educators, 5 (3), 1-7.

Bucchi, M. 1998. Science and the Media: Alternative Routes in Scientific Communication. New York: Routledge.

Burke, L.A. and James, K.E. 2008. "PowerPoint-based lectures in business education: An empirical investigation of student-perceived novelty and effectiveness". Business Communication Quarterly, 71 (3), 277-296.

Busà, M.G. 2010. "Sounding natural: Improving oral presentation skills". Language Value, 2 (1), 51-67.

Campagna, S. 2009. "Projecting Visual Reasoning in Research Conference Presentations". In Gotti, M. (Ed.), Commonality and Individuality in Academic Discourse. Bern: Peter Lang, 371-392. 
Charles, C. and Ventola, E. 2002. "A Multi-Semiotic Genre: The Conference Slide Show". In Ventola, E., Shalom, C. and Thompson, S. (Eds.), The Language of Conferencing. Bern: Peter Lang, 169-209.

Clark, J. 2008. "PowerPoint and pedagogy: Maintaining student interest in university lectures". College Teaching, 56 (1), 39-45.

Clark, R.E. 2003. "Fostering the work motivation of individuals and teams". Performance Improvement, 42 (3), 21-29.

Corbeil, G. 2007. “Can PowerPoint presentations effectively replace text-books and blackboards for teaching grammar?”. CALICO Journal, 24 (3), 631-656.

Diani, G. 2015. "Visual Communication in Applied Linguistics Conference Presentations". In Crawford Camiciottoli, B. and Fortanet-Gómez, I. (Eds.) 2015. Multimodal Analysis in Academic Settings: From Research to Teaching. London: Routledge, 83-107.

Dörnyei, Z. 2001. Motivational Strategies in the Language Classroom. Cambridge: Cambridge University Press.

Dörnyei, Z. and Schmidt, R. (Eds.) 2001. Motivation and Second Language Acquisition. Honolulu, HI: University of Hawai'i, Second Language Teaching and Curriculum Center.

Eccles, J.S. and Wigfield, A. 2002. "Motivational beliefs, values, and goals". Annual Review of Psychology, 53, 109-132.

Friendly, M. 2009. "Milestones in the history of thematic cartography, statistical graphics, and data visualization”. 2 February 2018. http://www.datavis.ca/papers/gfkl.pdf

Goffman, E. 1967. Interaction Ritual: Essays on Face-to-Face Behaviour. Chicago: Aldine.

Gotti, M. 2003. Specialized Discourse. Bern: Peter Lang.

Greenbaum, S. and Quirk, R. 1990/2008. A Student's Grammar of the English Language. London: Pearson.

Halliday, M.A.K. 2002. On Grammar. London: Continuum. 
- 2004. An Introduction to Functional Grammar. Third edition. London: Hodder Arnold.

Heino, A., Tervonen, E. and Tommola, J. 2002. "Metadiscourse in Academic Conference Presentations". In Ventola, E., Shalom, C. and Thompson, S. (Eds.) 2002. The Language of Conferencing. Bern: Peter Lang, 127-146.

Holmes, S. 2013. "Key strategies for student success: Insider information from the academically $\quad$ dismissed”. $\quad 2 \quad$ February 2018. https://cdn.dal.ca/content/dam/dalhousie/pdf/management/Faculty\%20\&\%20Sta ff/Key\%20Strategies\%20for\%20Student\%20Success.pptx.lt_389309371cbf3e6e 51b7890576be7761.res/Key\%20Strategies\%20for\%20Student\%20Success.pptx

Hyland K. 2005. Metadiscourse: Exploring Interaction in Writing. London: Continuum.

Iedema, R. 2001. Resemiotization. Semiotica, 137 (1-4), 23-39.

Ilter, B.G. 2009. "Effect of technology on motivation in EFL classrooms". Turkish Online Journal of Distance Education 10 (4). 10 December 2017. https://files.eric.ed.gov/fulltext/ED506782.pdf

Jakobson, R. 1959. “On Linguistic Aspects of Translation”. In Brower, R.A. (Ed.), On Translation. Cambridge: Harvard University Press, 232-239.

Jurado, J.V. 2015. "A Multimodal Approach to Persuasion in Conference Presentations". In Crawford Camiciottoli, B. and Fortanet-Gómez, I. (Ed.) 2015. Multimodal Analysis in Academic Settings: From Research to Teaching. London: Routledge, 108-130.

Kaplan, S. 2011. "Strategy and PowerPoint: An inquiry into the epistemic culture and machinery of strategy making”. Organization Science, 22 (2), 320-346.

Knoblauch, H. 2008. "The performance of knowledge: Pointing and knowledge in PowerPoint presentations". Cultural Sociology, 2 (1), pp. 75-97.

Kosslyn, S.M., Kievit, R.A., Russell, A.G. and Shepard, J.M. 2012. "PowerPoint presentation flaws and failures: A psychological analysis". Frontiers in Psychology, 3, 1-22. 
Kostelnick, C. 1993. "Viewing Functional Pictures in Context". In Blyler, N.R. and Thralls, C. (Eds.) 1993. Professional Communication: The Social Perspective. London: Sage, 243-256.

Kress, G. 2003. Literacy in the New Media Age. London: Routledge.

- 2010. Multimodality: A Social Semiotic Approach to Contemporary Communication. London: Routledge.

Kress, G. and Van Leeuwen, T. 2001. Multimodal Discourse: The Modes and Media of Contemporary Education. London: Hodder.

Landis, R.B. 2005. "Motivating students to succeed". 2 February 2018. www.ecs.csun.edu/ecs/docs/motivate.ppt

Lari, F.S. 2014. "The impact of using PowerPoint presentations on students' learning and motivation in secondary schools". Procedia, 98, 1672-1677.

Mertz, B. 2013. "Motivating and developing others". 2 February 2018. https://accelerate.ucsf.edu/files/MDP_MertzMotivatingDevelopingOthers2015.p $\mathrm{pt}$

Muir-Herzig, R.G. 2004. "Technology and its impact in the classroom". Computers \& Education, 42, 111-131.

Oommen, A. 2012. "Teaching English as a global language in smart classrooms with PowerPoint presentations". English Language Teaching, 5 (12). 10 December 2017. https://files.eric.ed.gov/fulltext/EJ1080100.pdf

Paoletti, G., Bortolotti, E. and Zanon, F. 2012. "Effects of redundancy and paraphrasing in university lessons: Multitasking and cognitive load in writtenspoken PowerPoint presentation”. International Journal of Digital Literacy and Digital Competence, 3 (3), 1-11.

Raffo, M. 2016. "Translation and popularization: Medical research in the communicative continuum". Meta, 61, 163-175.

Rowley-Jolivet, E. 2000. "Image as text: Aspects of the shared visual language of scientific conference participants". Asp, 27-30, 133-154. 
— 2002. "Visual discourse in scientific conference papers: A genre-based study". English for Specific Purposes, 21 (1), 19-40.

— 2004. "Different visions, different visuals: A social-semiotic analysis of fieldspecific visual composition in scientific conference presentations". Visual Communication, 3 (2), 145-175.

Sala, M. 2008. Persuasion and Politeness in Academic Texts: An Introduction. Bergamo: Celsb.

Salama, R. 2014. "Motivation towards teamwork". 2 February 2018. www.pitt.edu/ super4/36011-37001/36041.ppt

Soler, V. 2007. "Writing titles in science: An exploratory study". English for Specific Purposes, 26, 90-102.

Stark, D.and Paravel, V. 2008. "PowerPoint in public: Digital technologies and the new morphology of demonstration”. Theory, Culture \& Society, 25 (5), 30-55.

Susskind, J.E. 2005. "PowerPoint's power in the classroom: enhancing students' selfefficacy and attitudes". Computers \& Education, 45, 203-215.

Tardy, C.M. 2005. "Expressions of disciplinarity and individuality in a multimodal genre”. Computers and Composition, 22 (3), 319-336.

Tufte, E.R. 2001. The Visual Display of Quantitative Information. Cheshire, CT: Graphics Press.

— 2003. The Cognitive Style of PowerPoint. Cheshire, CT: Graphics Press.

Van Leeuwen, T. 2004. “Ten Reasons Why Linguists Should Pay Attention to Visual Communication”. In LeVine, P. and Scollon, R. (Eds.) 2004. Discourse and Technology: Multimodal Discourse Analysis. Washington, DC: Georgetown University Press, 7-19.

— 2005. Introducing Social Semiotics. London: Routledge.

Vassileva, I. 2002. "Speaker-Audience Interaction: The Case of Bulgarians Presenting in English". In Ventola, E., Shalom, C. and Thompson, S. (Eds.) 2002. The Language of Conferencing. Bern: Peter Lang, 255-276. 
Virbel, J. et al. 1999. "A linguistic approach to some parameters of layout: A study of enumerations". AAAI Technical Report, 4, 35-43.

Wang, M.J. 2011. "Using multimodal presentation software and peer group discussion in learning English as a second language”. Journal of Educational Technology, 27 (6), 907-923.

Webber, P. 2002. "The Paper is Now Open for Discussion”. In Ventola, E., Shalom, C. and Thompson, S. (Eds.) 2002. The Language of Conferencing. Bern: Peter Lang, 227-254.

— 2005. "Interactive features in medical conference monologue". English for Specific Purposes, 24 (2), 157-181.

Williams, G. 2013. "Self-Determination Theory in Practice". 2 February 2018. http://chcr.umich.edu/materials/2013-05-13-williams.pptx

Williams, K.C. and Williams, C.C. 2011. "Five key ingredients for improving student motivation". Research in Higher Education Journal, 11, 1-23.

Wood, R. 2017. "The influence of teacher-student relationships and teacher feedback upon students' engagement with learning”. 2 February 2018. https://slideplayer.com/slide/12303558/

Wysocki, A.F. 2003. “The Multiple Media of Texts: How Onscreen and Paper Texts Incorporate Words, Images, and Other Media”. In Bazerman, C. and Prior, P. (Eds.). What Writing Does and How It Does It: An Introduction to Analysis of Text and Textual Practices. Mahwah: Erlbaum and Associates, 123-163.

— 2007. "Seeing the Screen: Research into Visual and Digital Writing Practices". In Bazerman, C. (Ed.), Handbook of Research on Writing. London: Routledge. 8 October 2017. https://www.routledgehandbooks.com/doi/10.4324/9781410616470.ch37\#ref37 $\underline{1}$ 
Received: 10 April 2018

Accepted: 23 July 2018

Cite this article as:

Consonni, Stefania 2018. "Multimodal literacy in academic environments: PowerPoint as a motivational genre". Language Value 10 (1), 1-24. Jaume I University ePress: Castelló, Spain. http://www.e-revistes.uji.es/languagevalue.

DOI: http://dx.doi.org/10.6035/LanguageV.2018.10.2

\section{ISSN 1989-7103}

Articles are copyrighted by their respective authors 